\title{
Entre a filosofia e a sociologia: matrizes teóricas das discussões atuais sobre história e memória
}

BENITO BISSO SCHMIDT*

Resumo: O objetivo deste texto é situar as matrizes teóricas dos trabalhos de alguns autores que servem como referência para boa parte dos estudos contemporâneos sobre as relações entre história e memória: Bergson, Halbwachs, Pollak, Nora e Ricoeur. Seus estudos dialogam, de maneira direta ou indireta, com duas matrizes: a sociológicaobjetivista e a fenomenológica-intuicionista. Elas se estabeleceram no âmbito da disputa entre a sociologia e a filosofia pelo direcionamento das ciências humanas nascentes no século XIX.

Abstract: The objective of this text is to point out the theoretical matrices of some authors who serve as reference of contemporary studies on the relation between history and memory: Bergson, Halbwachs, Pollak, Ricoeur. Their studies dialogue, in a direct or indirect way, with two matrices: the sociological-objectivist and the phenomenologicalintuitionist. These matrices became known within the scope of the dispute between philosophy and sociology about the orientation of the emerging human sciences in the XIX century.

Palavras-chave: História. Memória. Fenomenologia.

Key words: History. Memory. Phenomenology.

1

Basta uma rápida passada de olhos nos trabalhos recentes que problematizam as relações entre história e memória para percebermos a constante referência a certos autores que formam uma espécie de "núcleo duro" teórico e metodológico ao qual os pesquisadores contemporâneos recorrem quando se voltam à temáti-

Professor no Departamento e no PPG em História da UFRGS; Coordenador do Núcleo de Pesquisa em História da UFRGS.

Estudos Ibero-Americanos. PUCRS, v. XXXII, n. 1, p. 85-97, junho 2006 
ca. Entre eles podemos citar os sociólogos Maurice Halbwachs (1877-1945) e Michael Pollak (1948-1992), o filósofo Paul Ricoeur (1913-2005) e o historiador Pierre Nora (1931). Algumas noções como memória coletiva, enquadramento, lugares da memória, esquecimento e testemunha já se tornaram lugares-comuns no vocabulário de historiadores, antropólogos, psicólogos e outros profissionais interessados pelos fenômenos relacionados ao lembrar e ao esquecer.

Porém, há uma considerável distância entre incorporar tais termos ao vocabulário e utilizá-los como efetivas referências analíticas. ${ }^{1}$ Digo isso, pois percebo - e insisto no caráter de "percepção" desta observação, já que ainda não pude sustentá-la de maneira mais aprofundada - que muitos dos estudos produzidos recentemente valem-se dos referidos autores e de suas noções de maneira um tanto quanto superficial, esvaziando-os de suas efetivas contribuições teórico-metodológicas, muitas vezes mesclando-os de forma descuidada, sem considerar suas matrizes epistemológicas e os debates a elas relacionados. Penso, por exemplo, na noção de lugares da memória, cunhada por Nora para dar unidade às manifestações do surto memorialístico ocorrido na França nos anos 1980 (analisadas nos diversos capítulos da obra coletiva Lieux de mémoire, por ele coordenada e publicada de 1984 a 1993), e que passou a ser utilizada para designar, em diferentes países e com referência a épocas variadas, os mais heterogêneos suportes da memória. Não quero, de maneira alguma, negar em bloco a validade deste uso, mas sim chamar a atenção para os "abusos", ou seja, para o uso irrefletido da categoria, que desconsidera suas possibilidades e limites. Lembro, nesse sentido, da advertência de Lucette Valensi, no debate sobre os Lieux publicado na revista $\mathrm{An}$ nales, em 1995: "Se Pierre Nora fizer escola, os resultados [das investigações] não correm o risco de serem mais repetitivos que cumulativos ou inovadores?"2

Motivado por essa suspeita e por essas preocupações, resolvi apresentar no presente texto algumas reflexões muito preliminares

1 Esta observação é inspirada pela reflexão de Viotti da Costa a respeito da ênfase no discurso presente na historiografia atual: "Discurso, linguagem, simbólico, descontrução, tornaram-se expressões comuns no jargão do historiador, embora freqüentemente apenas como parte do seu vocabulário, e não como parte de sua teoria" (COSTA, Emilia Viotti da. Novos públicos, novas políticas, novas histórias: do reducionismo econômico ao reducionismo cultural: em busca da dialética. Anos 90. Porto Alegre: PPG em História da UFRGS, no 10, dezembro de 1998, p. 13).

2 VALENSI, Lucette. Histoire nationale, histoire monumentale. Les lieux de mémoire (note critique). Annales HSS, n. 6, nov.-déc. 1995, p. 1272. Tradução minha. 
sobre as matrizes teóricas que informam os estudos dos autores referidos, destacando suas referências epistemológicas, bem como suas aproximações e seus afastamentos, situando-os no âmbito dos conflitos entre a filosofia e a sociologia que se desenrolaram entre meados do século XIX e as primeiras décadas do XX.

Como todos sabemos, a história, desde o século XVIII, mas sobretudo no Oitocentos, buscou configurar-se como disciplina autônoma e científica. Porém, em virtude de seu intrínseco e "perigoso" caráter narrativo e da impossibilidade de embasar suas generalizações em experimentos e observações diretas, sofreu a concorrência, inclusive institucional, das jovens ciências sociais, as quais, como afirma François Dosse, "se desenvolvem como ciências irmãs, mas... poderiam pretender englobar a história, anexá-la em seu discurso menos ideológico e mais científico". ${ }^{3}$

O paradigma científico que serviu de "molde" à disciplinarização dos estudos a respeito da sociedade e do passado humanos foi aquele constituído a partir da Revolução Científica do século XVI e desenvolvido nos séculos seguintes basicamente no âmbito das ciências naturais. Tal paradigma, nas palavras de Boaventura de Sousa, implica

um modelo global de racionalidade científica que admite variedade interna, mas que se distingue e defende, por via de fronteiras ostensivas e ostensivamente policiadas, de duas formas de conhecimento não-científico (e, portanto, irracional) potencialmente perturbadoras e intrusas: o senso comum e as chamadas humanidades ou estudos humanísticos (em que se incluíram, entre outros, os estudos históricos, filológicos, jurídicos, literários, filosóficos e teológicos). ${ }^{4}$

Em relação a este paradigma, o mesmo autor diferencia duas vertentes principais:

a primeira, sem dúvida dominante, consistiu em aplicar, na medida do possível, ao estudo da sociedade todos os princípios epistemológicos e metodológicos que presidiam ao estudo da natureza desde o século XVI; a segunda, durante muito tempo marginal mas hoje ca-

3 DOSSE, François. A identidade nacional como forma organizadora do discurso histórico na França nos séculos XIX e XX. In: —— . A história à prova do tempo: da história em migalhas ao resgate do sentido. São Paulo: UNESP, 2001, p. 19.

4 SANTOS, Boaventura de Sousa. Um discurso sobre as ciências na transição para uma ciência pós-moderna. Estudos Avançados, São Paulo, USP, v. 2, n. 2, maio/ago. 1988, p. 48. 
da vez mais seguida, consistiu em reivindicar para as ciências sociais um estatuto epistemológico e metodológico próprio, com base na especificidade do ser humano e sua distinção polar em relação à natureza. $^{5}$

As ciências sociais nascentes integraram-se, em grande medida, à primeira vertente mencionada, esforçando-se sobremaneira para pautar suas preocupações e seus métodos naqueles estabelecidos pelas ciências naturais. Assim, Auguste Comte, fundador da física social, advertia que essa só se estabeleceria quando os homens renunciassem às "questões mais radicalmente inacessíveis a nossos meios - a natureza íntima dos seres, a origem e o fim de todos os fenômenos", pois "somente a experiência pode nos oferecer a medida de nossas forças". ${ }^{6}$ Émile Durkheim, continuador de Comte na tarefa de objetivação dos fenômenos sociais, mas também crítico das recaídas metafísicas e religiosas do antecessor, explicitou de forma cabal essa perspectiva em frase célebre: "Não afirmamos, com efeito, que os fatos sociais são coisas materiais, mas sim que são coisas, tal como as materiais, embora de uma outra maneira".7

Nesta perspectiva, a história aparece como uma espécie de "prima pobre", receosa, pelo caráter indireto de seu conhecimento, de alçar-se a vôos mais altos, ou seja, a generalizações mais amplas; temendo, se assim o fizesse, construir um conhecimento pouco científico e moldado pela filosofia. Talvez por isso tenha sido vista, muitas vezes, como mera fornecedora de dados às ciências sociais.

Porém, na contramão da vertente acima caracterizada, outra linha de pensamento questionava o materialismo e o cientificismo iluministas dominantes no conhecimento da história e da sociedade. Já no século XVIII, Giambattista Vico afirmava que a perda de capacidade imaginativa gerava dúvidas sobre Deus e, em conseqüência, corrupção moral. ${ }^{8}$ No século seguinte, o historicismo procurou reabilitar a importância de certas capacidades e qualidades expurgadas pela ciência moderna como a imaginação, a sensibilidade e a intuição. Na mesma linha, Wilhelm Dilthey pretendeu estabelecer as bases de uma "ciência do espírito", calcada na com-

5 Ibidem, p. 52.

6 COMTE, Auguste. Curso de filosofia positiva. In: Os pensadores: Comte. São Paulo: Nova Cultural, 1991, p. 5-6.

7 DURKHEIM, Émile. As regras do método sociológico. In: Os pensadores: Durkheim. São Paulo: Abril Cultural, 1978, p. 76.

8 HUGHES-WARRINGTON, Marnie. Giambattista Vico. In: —_ . 50 grandes pensadores da história. São Paulo: Contexto, 2002, p. 376. 
preensão interna dos fenômenos humanos (daí a importância que ele atribuía à psicologia), contrapondo-se à explicação externa própria das ciências naturais. ${ }^{9}$ Em todos esses esforços, verifica-se o desejo de construir um conhecimento sobre o homem que desse conta da complexidade de suas criações, o que não poderia ser feito apenas pela observação e pelo estabelecimento de leis que tendiam, justamente, a reduzir tal complexidade a causalidades mecânicas.

Enfim, ao esboçar este panorama, pretendi situar as linhas gerais da contenda estabelecida, sobretudo a partir do século XIX, entre duas vertentes que buscavam pautar a constituição da história e das ciências sociais como disciplinas autônomas: a sociológica-cientificista-nomotética e a fenomenológica-hermenêuticacompreensiva. Procurarei evidenciar agora as repercussões de tal disputa nas formas de se conceber a memória e suas relações com a história.

A segunda metade do século XIX foi marcada pelas conseqüências dos processos articulados de industrialização e urbanização. Na Europa ocidental, centro irradiador de tais movimentos, a transferência de vastas faixas da população para as grandes cidades e o desenvolvimento do capitalismo monopolista e financeiro implicaram inúmeras transformações nas sensibilidades e nos afetos de seus habitantes (já bastante analisadas pela historiografia). Enquanto certos grupos saudaram a ciência, o progresso, os avanços tecnológicos e as promessas de emancipação vinculadas à nova era industrial; outros lamentaram a perda dos vínculos comunitários - substituídos pelo "cash nexus" -, o esfacelamento de identidades consolidadas, a quebra de referências e tradições (mais imaginárias que reais) "imemoriais". Lembro, entre vários outros, do estudo de E. P. Thompson sobre as mudanças nos parâmetros de tempo trazidas pelo trabalho nas fábricas e as perturbações por elas ocasionadas nas primeiras gerações de operários. ${ }^{10}$

É nesse contexto, e motivados por essas transformações, que muitos autores - vinculados a diversas áreas do saber e da criação artística - manifestaram interesse pelo fenômeno da memória. Di-

9 DILTHEY, Wilhelm. Introducción a las ciencias del espíritu. Madrid: Alianza Editorial, 1986.

10 THOMPSON, E. P. Tempo, disciplina de trabalho e capitalismo industrial. In: - Costumes em comum. São Paulo: Companhia das Letras, 1998. 
ante das sensações de desenraizamento e de perda de referenciais, a memória delineou-se como um campo privilegiado de reflexões e debates. Envoltos neste clima, temos, por exemplo, os trabalhos de Sigmund Freud (1856-1939), de Henri Bergson (1859-1941), de Marcel Proust (1871-1922) e de Halbwachs. Examinarei, inicialmente, o pensamento de Bergson referente ao tema.

A primeira edição de Matéria e memória foi publicada em 1896. As notas e referências presentes no livro mostram que o autor estava bem informado dos estudos realizados pela escola psicofísica sobre a memória. Muitas das pesquisas científicas da época procuravam situar as lembranças - a partir da observação de pacientes com amnésia, afasia, cegueira psíquica e outros distúrbios - em alguma região anatômica do cérebro. O filósofo, reagindo a tal perspectiva, buscou ultrapassar o dualismo matéria/espírito. Nesse sentido, afirmou a "realidade do espírito" e a "realidade da matéria", procurando "determinar a relação entre eles sobre um exemplo preciso, o da memória"; pois tanto o idealismo quanto o realismo lhe pareciam "teses igualmente excessivas". Conforme Bergson, a lembrança representaria "precisamente o ponto de intersecção entre o espírito e a matéria". ${ }^{11}$

Para o autor, a memória significa "sobrevivência das imagens passadas"; "estas imagens irão misturar-se constantemente à nossa percepção do presente e poderão inclusive substituí-la. Pois elas só se conservam para tornarem-se úteis: a todo instante completam a experiência presente enriquecendo-a com a experiência adquirida; e, como esta não cessa de crescer, acabará por recobrir e submergir a outra" (p. 69 - grifos meus). ${ }^{12}$

Na interpretação de Bergson, existem duas formas de memória: a memória hábito e a memória representação. A primeira redundaria sempre em ação, estando ligada à repetição; por exemplo: aprender a tocar uma música ao piano "de cor". Tal memória, nas palavras do filósofo, "não contém nenhuma marca que revele suas origens e a classifique no passado; ela faz parte do meu presente...; ela é vivida, ela é 'agida', mais que representada" (p. 87-

11 BERGSON, Henri. Matéria e memória. Ensaio sobre a relação do corpo com o espírito. São Paulo: Martins Fontes, 1999, p. 1 e 5. Salvo indicação ao contrário, todas as citações de Bergson foram extraídas desta obra; limitar-me-ei, portanto, a indicar no corpo do texto as páginas dos trechos citados.

12 A noção de conservação é fundamental em Bergson. Em Creative evolution (1907), ele afirma: "In reality, the past is preserved by itself automatically. In its entirety, probably, it follows us at every instant; all that we have felt, thought and willed from our earliest infancy is there, leaning over the present wich is about to join it, pressing against the portals of consciousness that would fain leave it outside". Extraído de http:/ / www.kirjasto.sci.fi/bergson.htm (acessado em: 31 ago. 2005). 
88). A segunda remete à conservação de imagens únicas - "a própria imagem, considerada em si, era necessariamente de início o que será sempre" (p. 86-7) - por exemplo: a lembrança da primeira lição de piano. A memória-representação não traz nenhuma das características do hábito (p. 86); aliás ela subentende a interrupção do hábito: "Para evocar o passado em forma de imagem, é preciso poder abstrair-se da ação presente, é preciso saber dar valor ao inútil, é preciso querer sonhar" (p. 90). Tais lembranças-imagens, na visão de Bergson, irrompem no presente: a "lembrança espontânea, que se oculta certamente atrás da lembrança adquirida, é capaz de revelar-se por clarões repentinos: mas ela se esconde, ao menor movimento da memória voluntária" (p. 96). E ainda: "ela permanece caprichosa em suas manifestações e, como as lembranças que traz têm algo de sonho, é raro que sua intrusão mais regular na vida do espírito não perturbe profundamente o equilíbrio intelectual" (p. 97).

Retenhamos algumas noções centrais da abordagens bergsoniana da memória. Conforme o filósofo, as imagens-lembranças constitutivas da verdadeira memória, a "memória por excelência" (p. 91) - conservam-se no espírito e irrompem repentinamente quando o indivíduo sonha, "voa", interrompe a ação presente. Bergson advoga, pois, uma interpretação que supere os excessos cientificistas, mostrando que a memória não está contida na matéria, e, igualmente, a postura idealista, evidenciando a realidade do espírito. Seu trabalho constrói uma rica "fenomenologia da lembrança" ${ }^{13}$ tendo como foco o indivíduo e enfatizando os elementos não-conscientes e afetivos da memória. Nesse sentido, parece-me pertinente situá-lo na matriz fenomenológica-hermenêuticacompreensiva antes mencionada.

Enfoques semelhantes aparecem em autores com formações e objetivos tão variados como Proust - que valoriza a memória involuntária e menospreza as tentativas racionais e intelectuais de recuperação do passado" - e Freud - com suas noções de "retorno

13 BOSI, Ecléa. Memória e sociedade. Lembranças de velhos. São Paulo: Companhia das Letras, 1994, p. 43.

14 Em entrevista a Elie-Joseph Bois, publicada no Le Temps de 13 de novembro de 1913, Proust afirmava: "No meu modo de pensar, a memória voluntária, que pertence antes de mais nada à inteligência e aos olhos, oferece-nos apenas aspectos falsos do passado; mas se um odor ou um gosto, reencontrados em circunstâncias totalmente diferentes, desperta inesperadamente o passado em nós, então podemos sentir como esse passado é diferente daquilo que pensamos que poderíamos recordar, daquilo que a memória voluntária nos ofereceu, como um pintor que trabalha com cores falsas" (apud: SHATTUCK, Roger. As idéias de Proust. São Paulo: Cultrix/Editora da Universidade de São Paulo, 1985, p. 161). 
do recalcado" e de "souvenir-écran". Em Freud, Bergson e Proust, conforme Jacy Alves de Seixas, "a memória é sobretudo relacionada à imagem de erupção, à idéia de que somos 'tomados', assaltados e conduzidos pela memória, à imagem do rio, do fluxo ou do élan que traz 'de repente' o passado, ou melhor, a representação ou representações desse passado. Retorno sem dúvida carregado de afetividade, que nos permite de alguma forma 'reviver' as emoções experimentadas". 15

A sociologia também nasceu para dar respostas aos anseios e questionamentos da sociedade urbano-industrial em formação. Halbwachs não fugiu à regra e interessou-se pela memória visando, justamente, explicar e resolver certos problemas de sua época. Os estudos que realizou sobre o tema opõem-se, em grande medi$\mathrm{da}$, ao enfoque fenomenológico descrito acima. Seixas, acertadamente, o descreve como um "discípulo infiel de Bergson e fidelíssimo de Durkheim". ${ }^{16}$ Assim, na trilha deste último, pretendeu encarar a memória como um fato social, levando adiante as tentativas bergsonianas de "des-subjetivar" os fenômenos relativos ao lembrar e ao esquecer. ${ }^{17}$

O ponto essencial da teoria de Halbwachs é, pois, considerar a memória como um fenômeno social, uma reconstrução (e não conservação) do passado a partir dos quadros sociais do presente. ${ }^{18}$ No livro póstumo A memória coletiva, publicado em 1949, após sua trágica morte no campo de concentração de Buchenwald, no ano de 1945, verifica-se o permanente esforço do autor em comprovar a inexistência de memórias exclusivamente individuais, mesmo que numa mínima parcela. Ele parte, sobretudo, de lembranças pessoais e da literatura para concluir: "nossas lembranças permanecem coletivas, e elas nos são lembradas pelos outros, mesmo que se trate de acontecimentos nos quais só nós estivemos envolvidos, e com objetos que só nós vimos. É porque, em realidade, nunca estamos sós". ${ }^{19}$ A memória individual seria apenas um "ponto de vista sobre a memória coletiva" (p. 51), condicionado, no presente, pelos quadros sociais, pelos grupos dos quais cada indi-

15 SEIXAS, Jacy Alves de. Halbwachs e a memória-reconstrução do passado: memória coletiva e história. História, São Paulo, EDUNESP, n. 20, 2002, p. 104.

16 Ibidem, p. 95.

17 SANTOS, Myrian Sepúlveda. Memória coletiva e teoria social. São Paulo: Annablume, 2003, p. 21.

18 SEIXAS, op. cit., p. 97

19 HALBWACHS, Maurice. A memória coletiva. São Paulo: Vértice, 1990, p. 26. A observação sobre as citações feita na nota 11 vale também para o livro de Halbwachs. 
víduo participa (da família à nação). $\mathrm{O}$ esquecimento, em contrapartida, dar-se-ia pelo desapego a determinados grupos.

Vale lembrar que Halbwachs realizou seus estudos num contexto intelectual "em que os vínculos entre indivíduo e sociedade apresentavam-se como a grande antinomia nas ciências sociais". ${ }^{20}$ Nesse sentido, o autor - coerentemente com a ótica durkheiminiana - prioriza as estruturas coletivas da memória, vistas como concretas e objetivas. Além disso, dá destaque ao presente no processo de formação das recordações; despreza os componentes afetivos das lembranças, percebidos como ficções; e considera a memória um elemento de agregação dos grupos sociais, através do qual evita-se o conflito (pensado, também na linha de Durkheim, como anomia). Ou seja, sua obra segue a lógica cientificista-nomotética das ciências sociais nascentes.

Como poderíamos situar a história diante destas visões tão diferenciadas a respeito da memória? Como ela teria (ou não) transitado entre tais matrizes?

Constituindo-se enquanto ciência social, elegendo como seu objeto de estudo "os homens" no plural, a história-disciplina, ao tratar da questão da memória, recorreu sobretudo a Halbwachs, com sua ênfase no coletivo e no racional. Nesse sentido, pode-se citar, por exemplo, a influência do sociólogo junto ao grupo fundador dos Annales, especialmente Marc Bloch, apesar da existência de controvérsias entre ambos. ${ }^{21}$ Em contrapartida, pareceu difícil a nós, historiadores, valorizar as contribuições da matriz fenomenológica, que enfatiza o individual - um dos "ídolos" a serem expulsos da "tribo" dos historiadores, dizia Simiand -, o afetivo, o irracional, a irrupção inesperada, aspectos que davam a impressão de remeter à tão temida metafísica.22

Porém, vale lembrar que Halbwachs diferenciava enfaticamente a memória da história, contrapondo o caráter espontâneo e "vivo" da primeira - conseqüência da interiorização dos quadros sociais - ao enfoque exterior, racional e laicizante da segunda. Nas palavras do autor,

a memória coletiva não se confunde com a história, e [...] a expressão "memória histórica" não foi escolhida com muita felicidade, pois

20 SANTOS, op. cit., p. 22.

21 Ver: SORGENTINI, Hernán. Reflexión sobre la memoria y autorreflexión de la Historia. Revista Brasileira de História, São Paulo, ANPUH/Humanitas, v. 23, n. 45, 2003.

22 Sobre essas dificuldades, consultar os instigantes artigos de SEIXAS, op. cit., e do mesmo autor: Percursos de memórias em terras de história: problemáticas atuais. In: BRESCIANI, Maria Stella e NAXARA, Márcia (orgs.). Memória e (res)sentimentos: indagações sobre uma questão sensível. Campinas: Ed. da UNICAMP, 2002. 
associa dois termos que se opõem em mais de um ponto. [...] geralmente a história começa somente no ponto onde acaba a tradição, momento em que se apaga ou se decompõe a memória social. Enquanto uma lembrança subsiste, é inútil fixá-la por escrito, nem mesmo fixá-la, pura e simplesmente (p. 80).

Tal distinção taxativa - apesar de questionada por historiadores do calibre de Bloch - subsistiu ao longo do tempo e ainda pauta boa parte dos debates atuais sobre as relações entre história e memória. 23

Hoje vivemos em outra conjuntura de interesse pela memória e de medo do esquecimento, em que as sensações de falta de referências estáveis e de perda de identidade parecem remeter àquela outra virada de século. Os direitos e deveres da memória impuseram-se no espaço público e na agenda dos historiadores. ${ }^{24}$ Porém, como disse no início do texto, penso que, muitas vezes, desconhecemos os percursos e percalços do que aqui chamei, na falta de melhor designação, de matrizes teóricas das reflexões sobre o par história/memória, as quais, no meu entender, continuam balizando, ainda que, em geral, de forma subliminar, as discussões contemporâneas. Não aprofundarei esse tópico, mas permito-me fazer algumas indicações sobre o tema.

Pierre Nora, no texto de apresentação dos Lieux, repõe, quase que literalmente a diferenciação estabelecida por Halbwachs:

Fala-se tanto de memória porque ela não existe mais. [...]. A memória é a vida, sempre carregada por grupos vivos e, nesse sentido, ela está em permanente evolução, aberta à dialética da lembrança e do esquecimento, inconsciente de suas deformações sucessivas, vulnerável a todos os usos e manipulações, suscetível de longas latências e de repentinas revitalizações. A história é a reconstrução sempre problemática e incompleta do que não existe mais. A memória é um fenômeno sempre atual, um elo vivido no eterno presente; a história, uma representação do passado. Porque é afetiva e mágica, a memória não se acomoda a detalhes que a confortam; ela se alimenta de lembranças vagas, telescópicas, globais ou flutuantes, particulares ou simbólicas, sensível a todas as transferências, cenas, censu-

23 Ver, por exemplo: PROST, Antoine. Como a história faz o historiador? Anos 90. Porto Alegre: PPG em História da UFRGS, n. 14, dez. 2000.

24 Uma análise inteligente deste processo está em HUYSSEN, Andreas. Seduzidos pela memória: arquitetura, monumentos, mídia. Rio de Janeiro: Aeroplano, 2000. 
ras ou projeções. A história, porque operação intelectual e laicizante, demanda análise e discurso crítico. A memória instala a lembrança no sagrado, a história a liberta, e a torna sempre prosaica. A memória emerge de um grupo que ela une, o que quer dizer... que há tantas memórias quantos grupos existem; que ela é, por natureza, múltipla e desacelerada, coletiva, plural e individualizada. A história, ao contrário, pertence a todos e a ninguém, o que lhe dá vocação para o universal. A memória se enraíza no concreto, no espaço, no gesto, na imagem, no objeto. A história só se liga às continuidades temporais, às evoluções e às relações das coisas. A memória é um absoluto e a história só conhece o relativo. ${ }^{25}$

Como conciliar tal polarização com a idéia, tão em voga atualmente, de que as memórias possibilitam o questionamento do discurso universalizador da história? Ou de que existem várias histórias plausíveis e legítimas? Ou de que a história também funciona como memória, muitas vezes reivindicando o absoluto e adquirindo uma aura sagrada? Ou ainda de que a história serve para "cortar", para afirmar as rupturas e não as continuidades?26 Enfim, quais são os limites dessa dicotomia implícita à noção de "lugares"?

Michael Pollak, por seu turno, indica que os trabalhos atuais questionam a "força quase institucional" da memória coletiva, sua duração, continuidade e estabilidade (como proposto por Halbwachs), e sublinham o caráter conflitivo dessa memória, seu caráter destruidor, uniformizador e opressor de diversas memórias subterrâneas. Segundo o autor, tratar-se-ia não mais de "lidar com os fatos sociais como coisas, mas de analisar como os fatos sociais se tornam coisas, como e por quem eles são solidificados e dotados de duração e estabilidade". Além disso, Pollak destaca que o silêncio e mesmo o esquecimento de certos temas e eventos não significam necessariamente "desapego ao grupo", mas formas de gestionar o dizível e o indizível em cada época. ${ }^{27}$

Porém, apesar de seu esforço para dessubstancializar a "coisa" memória, o sociólogo - aproximando-se das concepções de Pierre Bourdieu - não deixa de situar-se num marco, digamos, "objetivista", ao pretender "dar nome aos bois", ou seja, explicitar

25 NORA, Pierre. Entre memória e história: a problemática dos lugares. Projeto História, São Paulo, PUC-SP, n. 10, dez. 1993, p. 7 e 9.

26 FOUCAULT, M. Nietzsche, a genealogia e a história. In: MACHADO, Roberto (org.). Microfísica do poder. Rio de Janeiro: Graal, 1979.

27 POLLAK, Michael. Memória, esquecimento, silêncio. Estudos históricos. Rio de Janeiro: $\mathrm{CPDOC} / \mathrm{FGV}$, v. 2, n. 3, 1989, p. 4. 
os atores e processos que, racionalmente, configuram - "enquadram" 28 - as memórias coletivas.

Por fim, Paul Ricoeur, em sua obra A memória, a história, o esquecimento, publicada na França em 2000, procura superar algumas das oposições antes mencionadas (memória-hábito $\mathrm{X}$ memória representação, externo $X$ interno, memória individual $X$ memória coletiva, memória $X$ história), aproximando-se da referida matriz fenomenológica. Ele considera Bergson "o filósofo que melhor compreendeu o estreito vínculo entre o que chama "sobrevivência das imagens' e o fenômeno chave do reconhecimento". ${ }^{29}$ Também saúda as contribuições de Halbwachs, mas critica seu "dogmatismo surpreendente" no que tange à negação da memória individual: "é no ato pessoal da rememoração onde inicialmente buscouse e encontrou-se a marca do social. Mas este ato de rememoração é sempre nosso. Crer e atestar nisso não pode ser denunciado como uma ilusão radical" (p. 161). Dialogando de forma erudita e complexa com diferentes tradições filosóficas, Ricoeur quer "mostrar como a dimensão epistêmica, veritativa da memória, liga-se intimamente com a dimensão pragmática vinculada à idéia de exercício da memória" (p. 79).

No capítulo "Memória pessoal, memória coletiva", Ricoeur quer afastar-se do "dilema paralizante": "a memória é primordialmente pessoal ou coletiva?" (p. 125). Para tanto, percorre a tradição da "mirada interior" (Agostinho, Locke e Husserl), focada na subjetividade do indivíduo, e a da "mirada exterior" (Halbwachs), centrada no aspecto social, e procura "explorar os recursos de complementaridade ocultados pelos dois enfoques antagônicos, recursos mascarados, por um lado, pelo preconceito idealista da fenomenologia husserliana... e, por outro, pelo preconceito positivista da sociologia na glória de sua juventude" (p. 162). Um dos recursos utilizados nesta exploração foi buscado na linguagem comum: o conceito de atribuição, mais precisamente, de "atribuição múltipla". Assim, o fenômeno da memória poderia ser atribuído a si ("a minha memória"), mas também aos outros e, por extensão, a coletividades: "A originalidade desta fenomenologia da memória compartilhada reside principalmente no escalonamento dos graus de personalização e, inversamente, de anonímia entre os pólos de um 'nós' autêntico e o do 'si', do 'alguém', do 'os ou-

28 Pollak utiliza a expressão "enquadramento da memória", tomando-a de empréstimo a Henry Rousso em seu estudo sobre as lembranças da ocupação nazista na França. Ver: ROUSSO, Henry. Le syndrome de Vichy. De 1944 à nous jours. Paris: Seuil, 1990.

29 RICOEUR, Paul. La memoria, la historia, el olvido. Buenos Aires: Fondo de Cultura Económica, 2000, p. 551. Vale a mesma observação da nota 11. Tradução minha. 
tros"' (p. 170). Contudo, a obra de Ricoeur (apesar de muito citada), provavelmente devido à sua complexidade, ainda comparece pouco nas referências teóricas dos historiadores.

Enfim, meu objetivo neste texto não foi o de apresentar de maneira aprofundada o pensamento dos autores citados a respeito da memória e suas relações com a história, mas tão somente evidenciar a existência de diferentes matrizes teóricas referentes à questão, as quais precisam ser conhecidas pelos historiadores - em suas possibilidades e seus limites, suas aproximações e seus afastamentos - para que possamos efetuar análises mais densas sobre o lembrar e o esquecer, fenômenos tão relevantes na nossa contemporaneidade. 